\title{
China's regional public safety efficiency: a data envelopment analysis approach
}

\section{Yongguang Zou ${ }^{1,2} \mathbb{D} \cdot$ Yuemei $\mathrm{He}^{3} \cdot$ Weiling $\mathrm{Lin}^{4} \cdot$ Sha Fang ${ }^{5}$}

Received: 31 July 2019 / Accepted: 11 September 2020 / Published online: 21 September 2020

(c) Springer-Verlag GmbH Germany, part of Springer Nature 2020

\begin{abstract}
This study develops a comprehensive public safety efficiency index that includes the inputs and outputs of regional public safety. The DEA-BC ${ }^{2}$ model was used to measure the technical efficiency (TE), pure technical efficiency (PTE), and scale efficiency (SE) of public safety at 31 province-level administrative divisions (regions) in China from 2014 to 2018, and to analyze the effectiveness of public safety in each year. The findings indicate that the average TE, PTE, and SE of all regions from 2014 and 2018 were mostly redundant and ineffective. The average Malmquist index continued to decline, with the lack of technological progress identified as the main hindering factor. The public safety efficiency of 31 regions was affected by the technical progress change, pure technical efficiency change, and scale efficiency change at different periods. The findings suggest that all regions should improve the public safety inputs, better allocate various input elements and utilize public safety resources more effectively.
\end{abstract}

Yongguang Zou

ygzou2009@126.com

Yuemei He

heyuemei2019@163.com

Weiling Lin

lw151573@126.com

Sha Fang

sfang@cityu.mo

1 College of Tourism Management, Huaqiao University, Quanzhou 362021, People's Republic of China

2 Center of Tourism Safety and Security Research of China Tourism Academy, Quanzhou 362021, People's Republic of China

3 College of History Cultrue and Tourism, Yulin Normal University, No. 299, Education Middle Road, Yuzhou District, Yulin City, Guangxi, People's Republic of China

4 Anxi College of Tea Science, Fujian Agriculture and Forestry University, Anxi 362400, People's Republic of China

5 Faculty of International Tourism and Management, City University of Macau, Avenida Padre Tomás Pereira, Taipa, Macau 


\section{JEL Classification $\mathrm{O} 470$}

\section{Introduction}

Public safety is a newly emerged topic in the trajectory of urban development ( $\mathrm{Yu}$ and Fang 2017), and it is an important prerequisite for ensuring economic and social health as well as sustainable development of different regions. Scholars (Lin 2003; Lu et al. 2016; Proag and Proag 2014) suggest that cities with well-performed public safety are strongly resilient to natural disasters and social emergencies, and they maintain a dynamic equilibrium and coordinated development in ensuring environmental, social, and human safety. Therefore, public safety is one basic government function to prevent and control various accidents, disasters, and emergencies, and to maintain the safety of the lives and property of their people (Kożuch and Sienkiewicz-Małyjurek 2014; Liu et al. 2005).

The increasing number of incidents reveals that regions in China are exposed to risks that can threaten the stability and bring catastrophic consequences. According to the data from National Bureau of Statistics of China (National Bureau of Statistics 2019), public safety incidents have occurred more frequently and the number of deaths per million productions has remained high in recent years, which highlights the serious problems in regional public safety in China. Provincial governments strive to guarantee safety inputs, but they are unable to guarantee safety outputs because of the low public safety input awareness, insufficient and imbalanced allocation of safety inputs, and the inability of making reasonable and scientific safetyinput decisions (Kong and Li 2006). These constraints cause randomly assigned safety inputs and inefficient utilization of the limited public safety resources. In addition, governments' poor safety-input decisions lead to ineffectiveness of such input and consequent safety resources waste. Thus, a better understanding of efficiency of regional public safety is much needed.

Efficiency is a useful managerial control measure to assess how inputs and outputs act, aiming to obtain the desired results with the smallest possible amount of inputs or the ability to obtain the maximum possible amount of output from the available resources (Golany and Roll 1989). The use of available resources is generally measured by their efficient utilization. The inputs allocated for public safety are expected to result in safety improvements (Luo 2004). Thus, to enhance the efficient usage and management of safety inputs, the efficiency of these resources in improving public safety must be comprehensively evaluated (Zhang and Li 2004).

Public safety is the result of actions taken by all stakeholders of socioeconomic development (Kożuch and Sienkiewicz-Małyjurek 2014), which is associated with various input and output criteria. However, the criteria for safety input and output are subjectively determined by stakeholders (Cui and Li 2015; Fung et al. 2010; Kong and Li 2006); in previous studies, the weights of safety inputs and outputs are also subjectively evaluated (Aminbakhsh et al. 2013; Chang 2013; Feng et al. 2014; Gurcanli et al. 2015; Hu et al. 2009), which hinders the accurate or objective assessment of safety efficiency. Thus, to fill this research gaps, Data Envelopment Analysis (DEA) is used to comprehensively assess the efficient utilization of regional public 
safety. DEA measures the efficiency of decision-making units (DMUs) based on the input to DMU, which is often the resources used or consumed in the operation; whereas the output of DMU refers to the product or service offered by the system (Nahangi et al. 2019). DEA does not rely on the subjective assessments of an evaluator, and it reflects the efficient utilization of funds, other input resources, and safety management.

The previous literature primarily focuses on one specific area of public safety efficiency but largely ignores the public safety efficiency in wider regions and longterm observation. At the same time, public safety emergency usually influences the whole nation. For instance, due to the interpersonal transmission characteristics of the new coronavirus pneumonia (COVID-19), every region needs to participant and a systemic measurement is essential to stop the spread of COVID-19. Therefore, to fill the above-mentioned research gaps, this study uses the DEA to evaluate the public safety efficiency of 31 regions in China between 2014 and 2018 from the perspective of public safety inputs-outputs. The dynamic evolutions of the public safety efficiency of all regions are examined accordingly, with the aim to improve the public safety management in China. In other words, this study attempts to analyze the public safety efficiency by building a comprehensive model that includes the inputs and outputs index of public safety, and to measure and analyze the public safety efficiency of 31 province-level administrative divisions (regions) in China.

\section{Literature review}

\subsection{The perspectives and contents of public safety assessment}

Regional public safety is closely related to personal and property safety, but in the broad sense, it refers to the satisfaction of the safety and security needs of important systems, such as cities and its citizens, properties, and urban lifelines (Liao and Hou 2009). This concept is also described as the lawful social, economic, and cultural activities of cities and their production of the necessary goods for ensuring internal and external order (Frey 2015). Based on the general definition of safety, Lin (2003) suggests that public safety should represent the measures for the physical and mental health of residents. Regional public safety is influenced by complex and diverse factors and is constantly pursued by government and residents.

Regarding regional public safety assessments, previous research has focused on risk perspectives. From the perspective of risk, public safety assessment mainly focuses on single capability, simple vulnerability, and comprehensive vulnerability-capability. First, single capability assessment mainly evaluates the coping ability of public safety, which may include infrastructure, institutions, knowledge, skills, and integrated soft power, such as social relations, leadership, and management capabilities (Hu et al. 2009; Li et al. 2013). Second, simple vulnerability assessments, i.e., the vulnerability of regional public safety, can be assessed in two ways:

(1) based on the types of accidents (e.g., natural and human accident indicators), and

(2) by dividing its elements into indicators of exposure, sensitivity, and vulnerability (Schmidt-Thomé 2006; Luo et al. 2005; Zhao 2006). Vulnerability assessment 
indicators mainly include traffic accident casualties, traffic accident losses, firerelated casualties, direct economic losses, fire incidents, environmental pollution accidents, inundated area of flood disasters and droughts, and unemployment (Zhu and Lv 2011; Zhu et al. 2006). Third, comprehensive vulnerability-capability assessments mainly involve disaster risks and management indicators and a capacity and vulnerability analysis framework (Chang 2013; Zou 2016; Zhu et al. 2011). Previous studies on regional public safety mostly focused on evaluating the objective conditions of public safety and measuring the public safety of these regions in terms of their risk, vulnerability, and response ability (Chang 2013; Zhao 2006; Zhu and Lv 2011). In addition, extant studies primarily assess regional public safety efficiency on a cross-sectional basis, and longitudinal approach has been extremely scarce.

Regional public safety assessment also studied on the relationship between the safety investment and safety performance. Studies demonstrate the positive impacts of safety investment on safety performance (Tang et al. 1997; Lu et al. 2016; Feng et al. 2014), which can be indicated by indices such as accident frequency rate and accident severity rate. López-Alonso et al. (2013) propose that an inverse relationship exists between the average number of accidents and the cost of accident prevention, also known as safety investment. More specifically, safety investment decisions are made based on the number of possible accidents that may occur during future decision stages (Ma et al. 2016). Generally, more potential accidents indicate that more safety investments are needed for accident prevention. The number of potential accidents that may occur in the future is based on prediction, which suggests that safety investment decisions are conditional with uncertainty (Sato 2012). Government distributes its resources, such as human and financial resources, to many regulation activities. Because of the uncertainty of the accidents, safety investment made in advance may be less than what is actually needed for accidents prevention (Ma et al. 2016). Moreover, it is not easy to show a causal and quantifiable relationship between safety investments and overall public safety improvements (Miller et al. 2000). Very limited studies have evaluated public safety efficiency from the perspective of safety inputs-outputs. Therefore, a comprehensive and objective assessment of public safety efficiency becomes necessary.

\subsection{The methods of public safety assessment}

In the safety domain, various methods and models have been used for safety assessment, including cost estimation models, activity-based costing, and cost-benefit analysis. Safety cost estimation model is widely used to calculate the average direct accident costs, indirect accident costs, total accidents costs, and the costs of occupational safety and health risk (Aminbakhsh et al. 2013; López-Alonso et al. 2013; Sousa et al. 2014). Activity-based costing (ABC), on the other hand, emerges as a new approach that associates business activity-related costs with manufactured products (Gurcanli et al. 2015), which gives more accurate information especially in complex structures and provides detailed information on cost items (Tsai et al. 2014). This approach allows firms to compare their profitability, productivity, and 
cost control with other firms (Ríos-Manríquez et al. 2014) and facilitates decisionmaking of firms accordingly (Khataie et al. 2011). Cost-benefit analysis (CBA) is a technique used to organize, appraise, and present the costs and benefits, and inherent trade-offs of projects to increase public welfare undertaken by public sector authorities such as local, regional, and central governments, and international donor institutions (Aven and Hiriart 2011; Proag and Proag 2014). CBA is widely used for safety-related decision-making (Tappura et al. 2015). A popular and basic safety investment model minimizes the total expected cost, which is the sum of the costs of accident/injury prevention and loss (Aven and Hiriart 2011; Schmitz 2000). In the basic safety investment model, the probability of an accident is a function of the amount of investment, and the optimal amount of investment is determined by minimizing total expected cost. Even though these methods are used in the previous literature, there is neither a widely accepted nor a reasonable method for the assignment of weights (Egilmez and McAvoy 2013).

DEA is a data-oriented and comprehensive approach for evaluating the performance and relative efficiency, treating each evaluated unit as an independent DMU (Azadeh et al. 2017). It is based on multiple input or output variables that are calculated by comparing the efficiency of each DMU against the best units (Azadeh et al. 2017). DEA utilizes various forms of DMUs to evaluate the efficiency to address decision analysis in different sectors (Gong and Lv 2017; Paradi and Zhu 2013). Given that DEA is estimated based on a nonparametric methodology, there is no need to unify indicator units, consider the functional relationships between inputs and outputs, pre-estimate parameters, or assume weights, thereby ensuring the integrity of the original information (Feng et al. 2015). More specifically, DEA provides a theoretical framework and does not require a weighting procedure, which results in the highest rated multi-criteria evaluation method (Egilmez and McAvoy 2013). Therefore, in this study DEA methodology is employed as it provides an acceptable alternative solution for safety efficiency determination.

\section{Methodology}

\subsection{Selected indicators of public safety efficiency}

The proposed evaluation system in this study includes input and output indicators for the evaluation of public safety efficiency. Given that previous studies have not used unified indicators to measure public safety efficiency, the indicators are selected based on the literature review, the actual input-output processes associated with the regional development, and the data availability (Feng et al. 2015).

\subsubsection{Input indicators}

The components of safety input have been discussed in many previous studies, which primarily refer to investment in human resources, material resources, and financial resources (Tang et al. 1997; Egilmez and McAvoy 2013; Hermans et al. 2009; Lu et al. 2016). Based on the literature and data availability, four factors, namely, local 
environmental protection investments, public safety investments, financial healthcare investments, and social safety and employment investments, are considered as safety inputs in this study (Frey 2015; Tang et al. 1997; Yu and Fang 2017; Zhao 2006; Zhu et al. 2011; Zhu and Lv 2011).

Local environmental protection investments refer to the expenditures made by local governments on environmental protection, including expenditures on environmental protection administration, pollution control, natural ecological protection, energy conservation and utilization, pollution reduction, and comprehensive utilization of renewable energy and resources (National Bureau of Statistics 2019; $\mathrm{Yu}$ and Fang 2017). The more input into environmental protection, the higher the capacity of waste water and waste gas treatment, the less environmental pollution and the reduction in environmental disaster losses (Zhao 2006; Zhu et al. 2011; Zhu and Lv 2011). Public safety investments refer to the expenditure necessary for local governments to maintain national public safety, including the armed police, national safety, procuratorial, court, judicial administration, and other personnel salaries and administrative expenses (National Bureau of Statistics 2019; Yu and Fang 2017). Public safety expenditure is the expenditure to ensure the normal operation of the state machinery, safeguard national safety and consolidate the political power construction of governments at all levels (Yu and Fang 2017). The more local investment in public safety, the lower the death rate of all kinds of accidents, the lower the crime rate and the more stable the society (Zhao 2006; Zhu et al. 2011; Zhu and Lv 2011). Financial healthcare investments refer to the expenditure of medical and health institutions in order to guarantee and improve people's health and treat the persons suffering from diseases and injuries (National Bureau of Statistics 2019). The more money spent on health care, the greater the capacity to respond to public health events and the lower the number of deaths. Social safety and employment investments refer to the proportion of the expenditure on social safety and employment in the total local fiscal expenditure (Frey 2015). It mainly includes social insurance fund subsidy expenditure, employment subsidy expenditure, urban residents' minimum living allowance expenditure, minimum living allowance expenditure, and natural disaster living assistance expenditure (National Bureau of Statistics 2019). Social safety and employment expenditure are to ensure that citizens with no income, low income, and various accidents can survive, and to ensure that the basic life of workers in old age, unemployment, illness, work injury, and childbirth is not affected (Frey 2015; National Bureau of Statistics 2019). The more social safety and employment investment, the lower the unemployment rate, the higher the gross domestic product (GDP) will be.

\subsubsection{Output indicators}

Traditionally, safety output is reflected in safety performance (Mengolini and Debarberis 2008), commonly measured by injury rate. The presence of hazardous environments, high injury rates, and fatalities can result in productivity losses and increased costs (Dearmond et al. 2011; Fung et al. 2010; Saunders et al. 2017). Identifying the efficiency of provincial public safety is a challenge that must be addressed while assessing and evaluating performance criteria. This study employs the existing 
public safety evaluation systems in selecting representative output indicators. Three indicators of vulnerability-unemployment rate, traffic accident casualties, and direct economic losses resulting from natural disasters-are taken as the unexpected safety output indicators of regional public safety efficiency (Zhao 2006; Zhu et al. 2011; Zhu and Lv 2011). Unemployment rate refers to China's unique unemployment statistical indicators. The indicators include the ratio of the number of registered unemployed in cities and towns to the number of registered unemployed in urban units (after deducting the employed rural labor force, employed retired personnel, Hong Kong, Macao, Taiwan, and foreign personnel), non-working employees in urban units, urban private owners, individual heads of households, urban private enterprises, and the ratio of self-employed persons and urban registered unemployed persons. The number of casualties of traffic accidents refers to the number of casualties caused after a traffic accident occurs. The direct economic losses caused by natural disasters refer to the sum of the economic losses caused by natural disasters, including primary disasters and secondary disasters. Unemployment rate is closely related to the stability of the social environment; traffic accident casualties reflect the traffic safety; and direct economic losses resulting from natural disasters represent the extent of damage left by natural disasters.

When the input is certain, the expected output decreases while the level of regional public safety increases (Zhao 2006; Zhu et al. 2011; Zhu and Lv 2011). In addition, the sewage treatment capacity, GDP per capita, and number of beds in medical and health institutions are used as the expected outputs of public safety inputs. Sewage daily capacity refers to the design capacity of a sewage treatment plant to treat the amount of sewage each day and night. Regional GDP per capita, the total value of social final products, and labor services produced by a region in a certain period (usually one year) are calculated on the average of the population. The number of beds in medical and health institutions refers to the number of beds in medical and health institutions provided in a region. Specifically, the comprehensive utilization rate of industrial solid waste represents the regional ecological environment quality; GDP per capita reflects the regional risk resistance, and the number of beds in medical and health institutions demonstrates the regional capacity to respond to emergency situations. When the input is certain, the expected output, ecological environment quality, risk resistance, and regional emergency response capacity all increase.

\subsection{Models}

\subsubsection{DEA-BC ${ }^{2}$ model}

DEA-BC ${ }^{2}$ model is based on the variable returns to scale model (Azadeh et al. 2017), which measures the TE of DMUs and its TE can be further decomposed into PTE and SE. TE refers to the optimal configuration between input and output factors and shows the comprehensive ability of public safety resource utilization. TE reflects that the public safety resources have been fully utilized, the input factors have reached the optimal combination, and the maximum output effect has been 
achieved. The TE of a DMU is a comparative measure regarding how well it actually processes inputs to achieve its outputs, as compared to its maximum potential for doing so, as represented by its production possibility frontier (Barros and Mascarenhas 2005). Thus, TE of public safety is the ability to transform multiple safety input resources into multiple safety capability. A region is entitled as technically inefficient in public safety if it operates below the frontier. PTE reflects the allocation and utilization levels of public safety resources. It is a measure of TE without SE and purely reflects the managerial performance to organize the inputs in the production process. The PTE measure is obtained by estimating the efficient frontier under the assumption of variable returns to scale (Al-Muharrami 2008). Thus, PTE measure has been used as an index to capture safety managerial performance.

SE expresses whether a region is operating at its "optimal size" (Al-Muharrami 2008). The measure of SE allows the management to choose the optimum amount of public safety resources, i.e., to decide on the regional public safety input and to choose the scale of safety input that will attain the expected safety output level. Inappropriate amount of a public safety input (too large or too small) may sometimes be a cause of technical inefficiency (Muharrami 2008; Banker 1984). A region is scale efficient if public safety output increases by the same proportional change as all public safety inputs change (known as CRS) (Banker 1984). If it is scale inefficiency, further comparisons of decreasing returns to scale (DRS) and increasing returns to scale (IRS) should be applied (Banker 1984). Decreasing returns to scale (also known as diseconomies of scale) implies that public safety output increases by less than that proportional change in all public safety inputs (Banker 1984). In contrast, if public safety output increases by more than the proportional change in all public safety inputs, increasing returns-to-scale (also known as economies of scale) is achieved (Muharrami 2008, Banker 1984).

DEA has an input- and output-oriented model, where the former explores how to minimize the input when the output is certain, while the latter explores how to maximize the output when the input is certain. With regard to the regional public safety efficiency, the input factors of production are easier to control than the output factors. Therefore, this study adopts the $\mathrm{BC}^{2}$ model to analyze the efficiency of public safety inputs, to further understand PTE and SE and to improve the existing scales and technologies.

\subsubsection{Malmquist index}

The Malmquist index is mainly used to analyze the trend of changes in dynamic efficiency (Caves et al. 1984). This study uses the Malmquist index to analyze the inter-temporal regional public safety efficiency. According to Färe et al. (1992), the Malmquist index can be decomposed into the technical efficiency change index (TEC) and technical progress change (TPC). Under the premise of variable scale compensation, if the change in efficiency is calculated based on the geometric mean of the Malmquist index, then TEC can be decomposed into pure technical efficiency change (PTEC) and scale efficiency change (SEC). 
TPC is considered a true measure of future improvements in public safety efficiency and reflects the degree of variation in safety production technology. PTEC reflects the usage efficiency of inputs and denotes whether a region can use safety technologies effectively to maximize the outputs, SEC reflects whether the proportion of inputs and outputs is appropriate, and Malmquist index reflects the degree of variation of the total factors productivity of regional public safety. TPC, PTEC, and SEC $>1,=1$, and $<1$ indicate an increase, no change, and a decrease in the regional public safety efficiency, respectively. If the Malmquist index is larger than $1(M>1)$, this index is identified as the main driver of technical improvement; otherwise, this index is identified as the main cause of technical loss. $M>1, M=1$, and $M<1$ indicate an increase, no change, and a decrease in the level of total factor productivity compared with the previous period, respectively.

\subsection{Data source and processing}

The raw data of comprehensive utilization rate of industrial solid waste were from the China Statistical Yearbooks for the years 2014 to 2018, while the raw data for all other indicators were retrieved from the official website of the National Bureau of Statistics of China. The advanced search function of the website was used to obtain regional, sub-provincial, and provincial data. Other data taken from the website included the registered urban unemployment rate $(\%)$, number of deaths from traffic accidents (persons), direct economic losses resulting from natural disasters (100 million Yuan), percentage of general sewage treatment capacity used in production (\%), GDP per capita (Yuan/person), and number of beds in medical and health institutions (millions). The inputs for local environmental protection inputs, local public safety, local social safety and employment, and local health were obtained by using data for local fiscal environmental protection expenditures (100 million Yuan), local fiscal health expenditures (100 million Yuan), local fiscal social safety and employment expenditures (100 million Yuan), and local fiscal public safety expenditures (100 million Yuan).

Some regions in China had missing values for direct economic loss resulting from natural disasters. Based on the fluctuation law of specific values, this study used the middle year to denote the mean value for the preceding and succeeding years. Meanwhile, given the possible annual variations in prices and to eliminate the price impact, this study used 2014 as the base year and processes the data for direct economic losses resulting from natural disasters, GDP per capita, and local fiscal expenditures for environmental protection, health, social safety and employment, and safety from 2014 to 2018 at constant prices through consumer price index (CPI) for comparison. An inverse relationship exists between the input variables and the three output indicators for unemployment rate, traffic accident casualties, and direct economic losses resulting from natural disasters. Therefore, to maintain a consistent input-output direction, this study used the inverse algorithm to deal with three undesired output indicators (Lewis and Sexton 2004). 


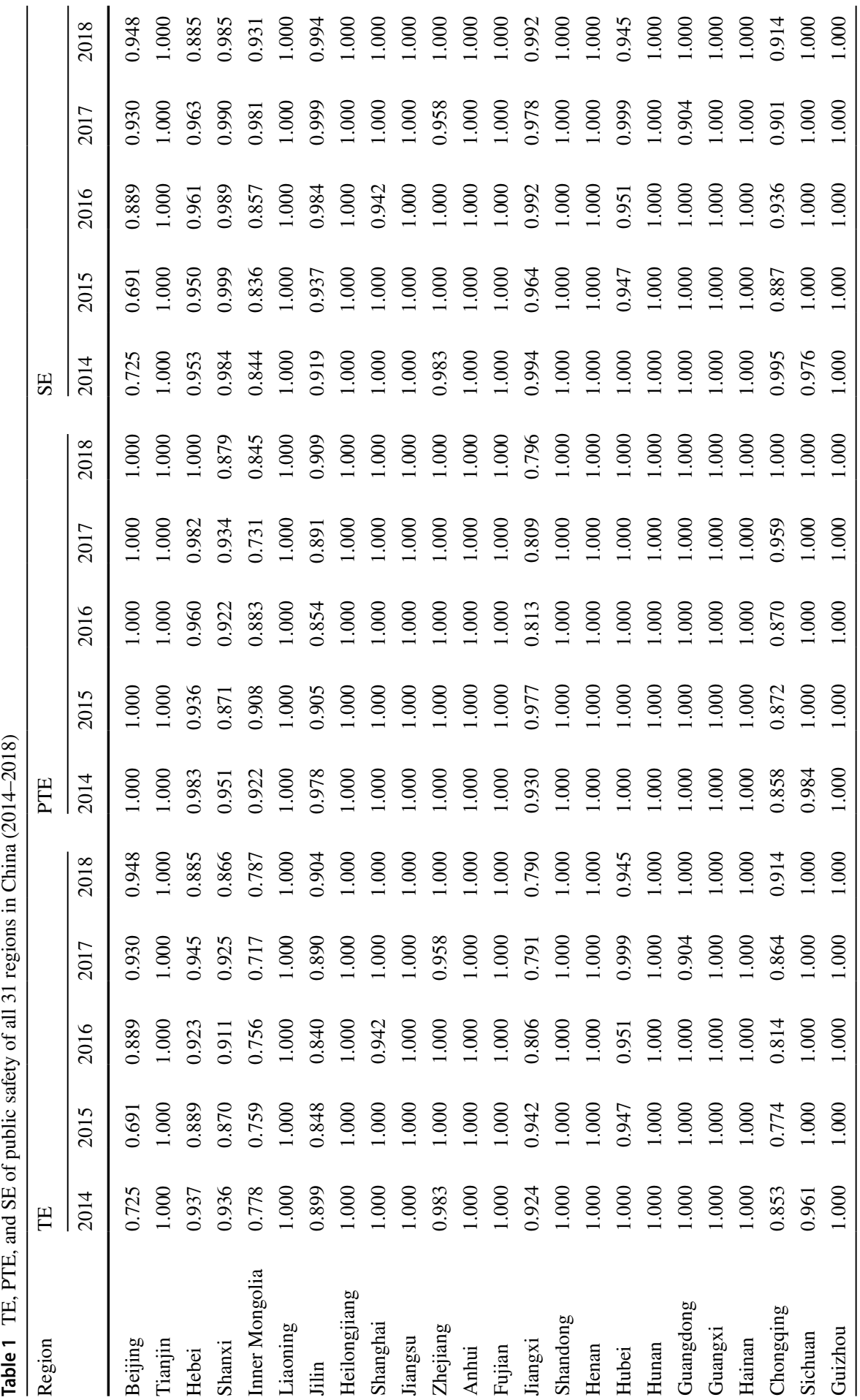




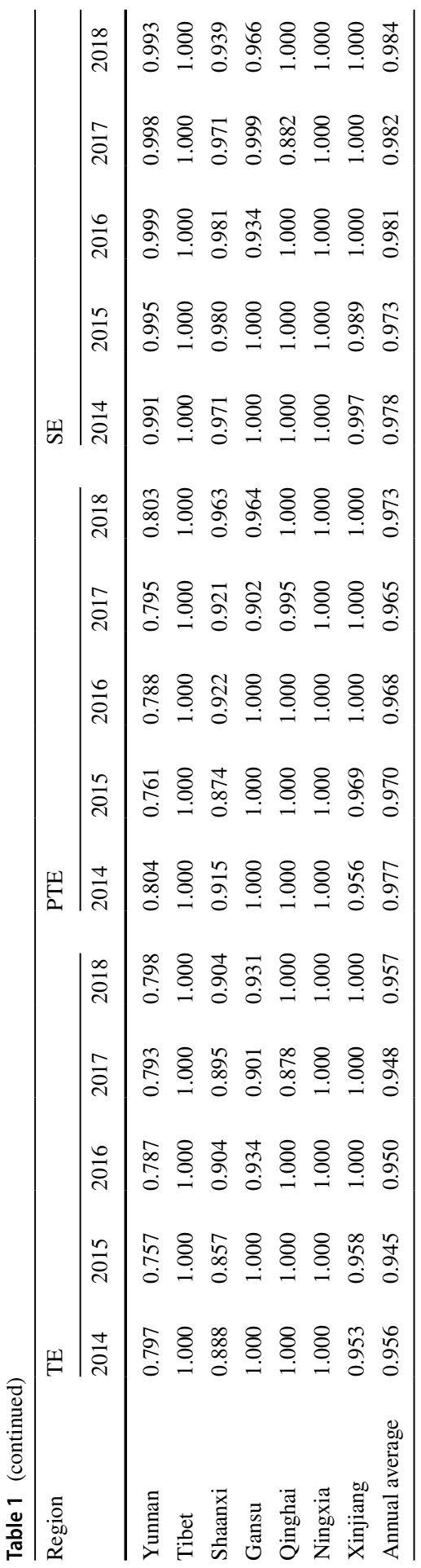




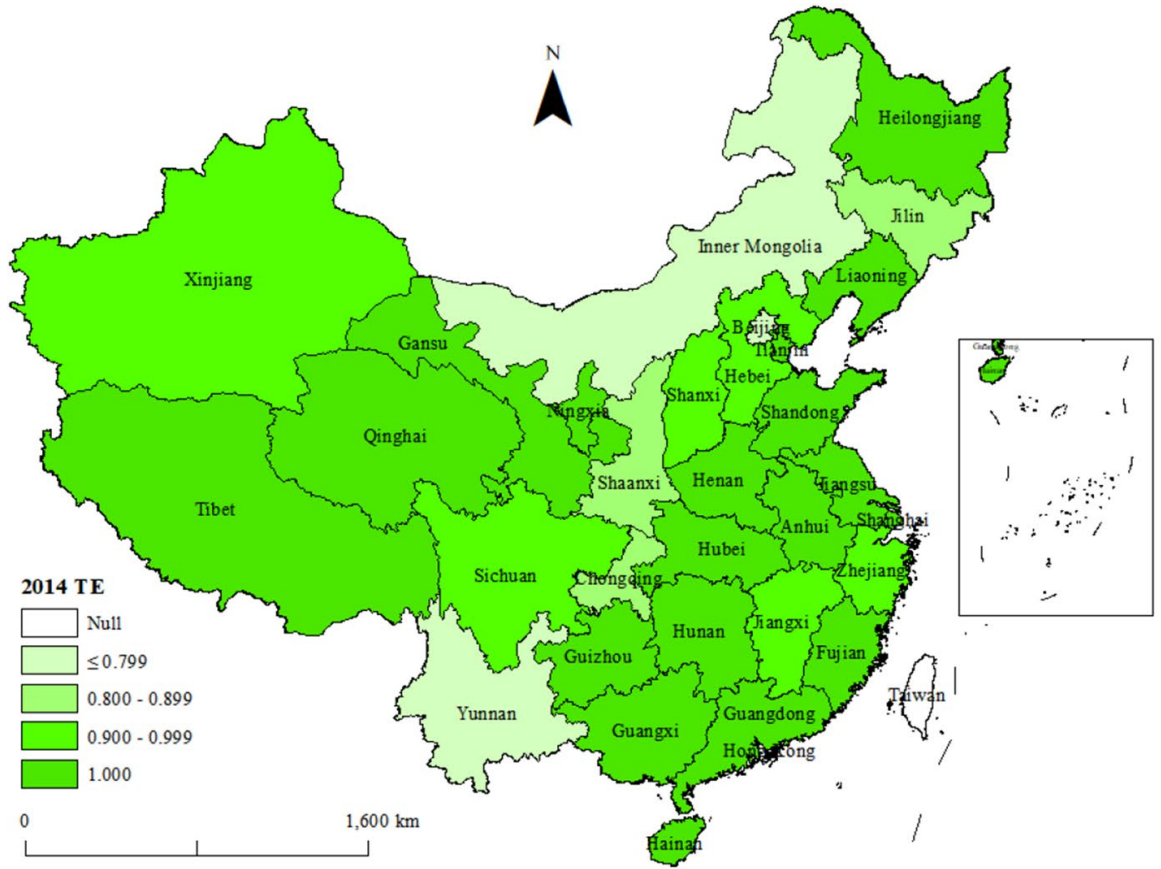

2014, TE

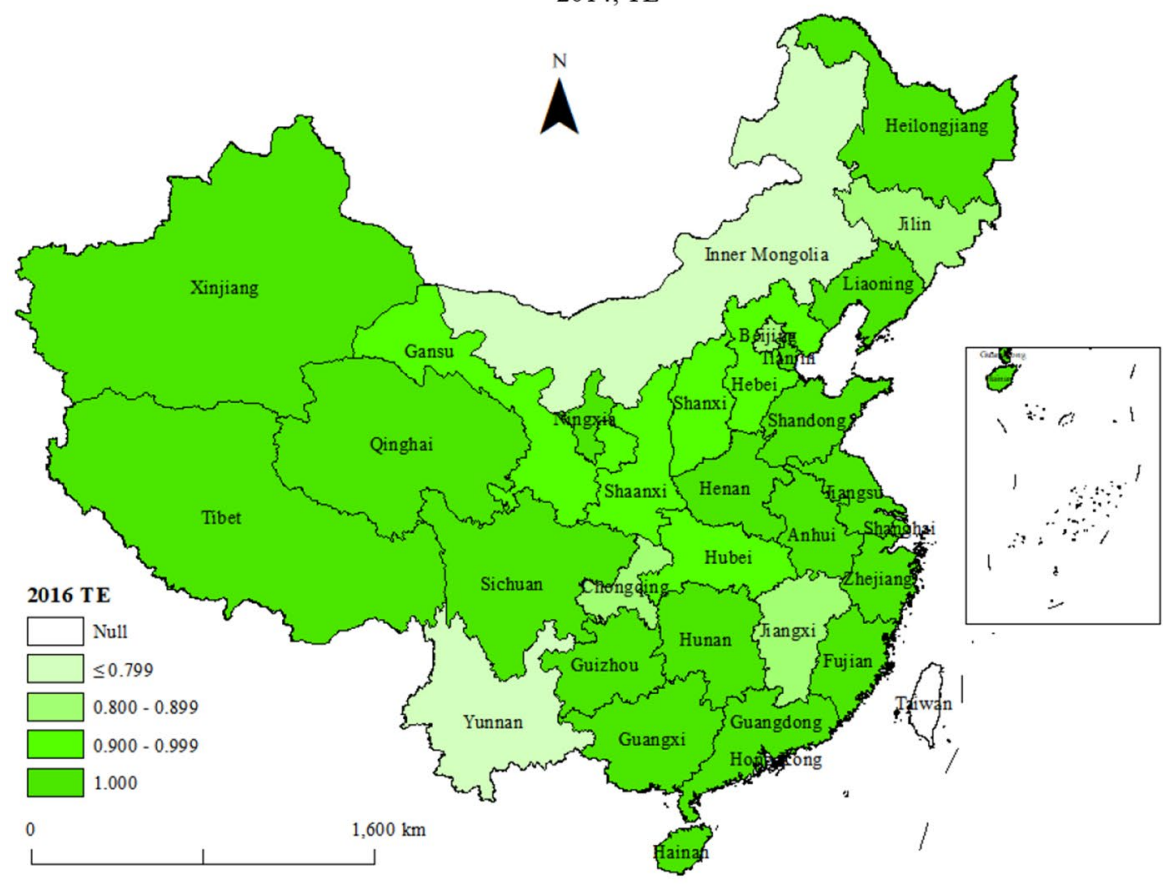

2016, TE

Fig. 1 Spatial characteristics of TE of public security in China 


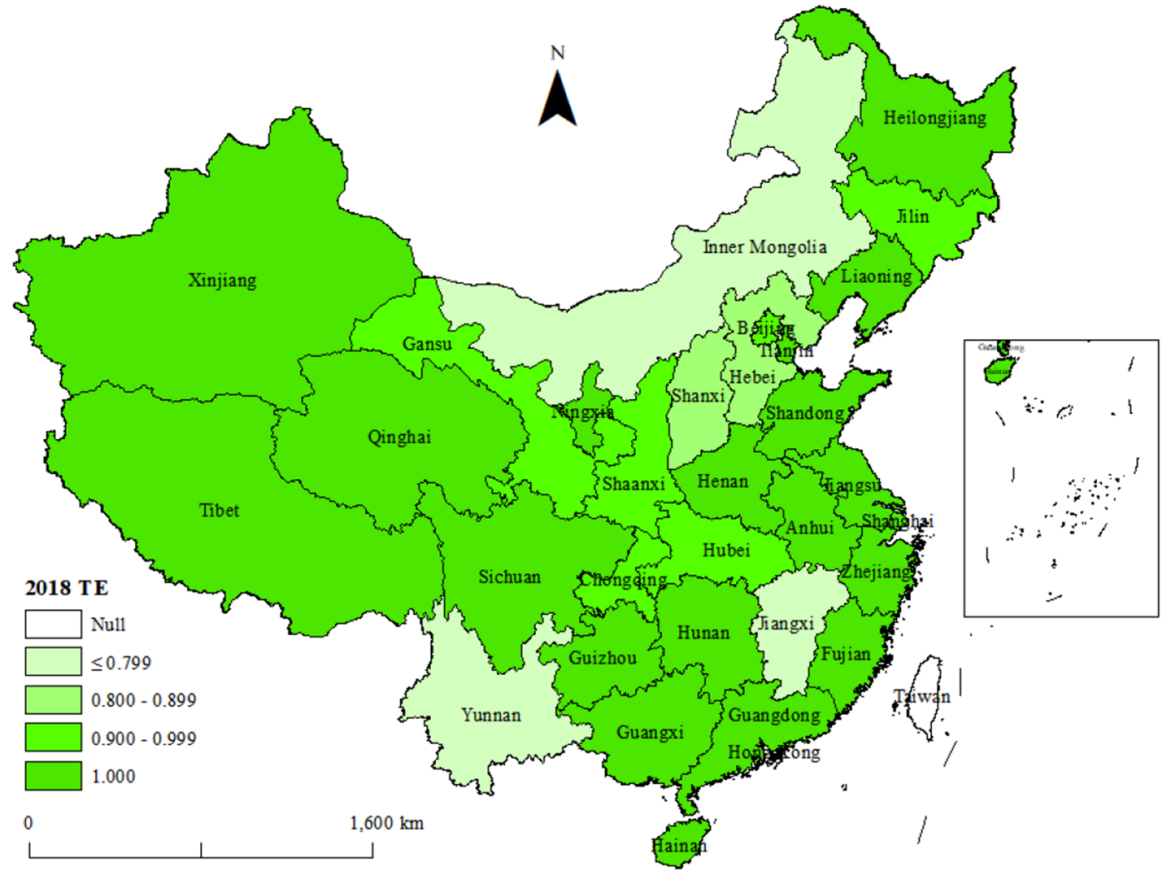

2018, TE

Fig. 1 (continued)

\section{Evaluation of the regional public safety efficiency}

\subsection{Measured values and spatial characteristics of regional public safety efficiency}

The DEAP2.1 was used to calculate the TE, PTE, and SE of 31 regions in China from 2014 to 2018 . The results for the three indicators of public safety efficiency are shown in Table 1 . To clearly demonstrate the evolution of these efficiencies and the impact of PTE and SE across all phases, this study applied ArcMap to select all of the 31 regions in China for the years of 2014, 2016, and 2018. The results for the three indicators of spatial visualization are shown in Figs. 1, 2 and 3.

\subsubsection{Measured values and spatial characteristics of TE}

Table 1 indicates that the average public safety TE of all 31 regions in China increased every year from 2014 to 2018 but decreased in 2015. Specifically, the average public safety TE of these regions from 2014 to 2018 was $0.956,0.945$, $0.950,0.948$, and 0.957 , respectively. The result indicates that despite a relatively high public safety TE, the efforts in guaranteeing public safety were rather ineffective. In 2014, all regions in China had an average public safety TE of 0.956 , indicating that the TE of public safety in China was far from ideal and can still 


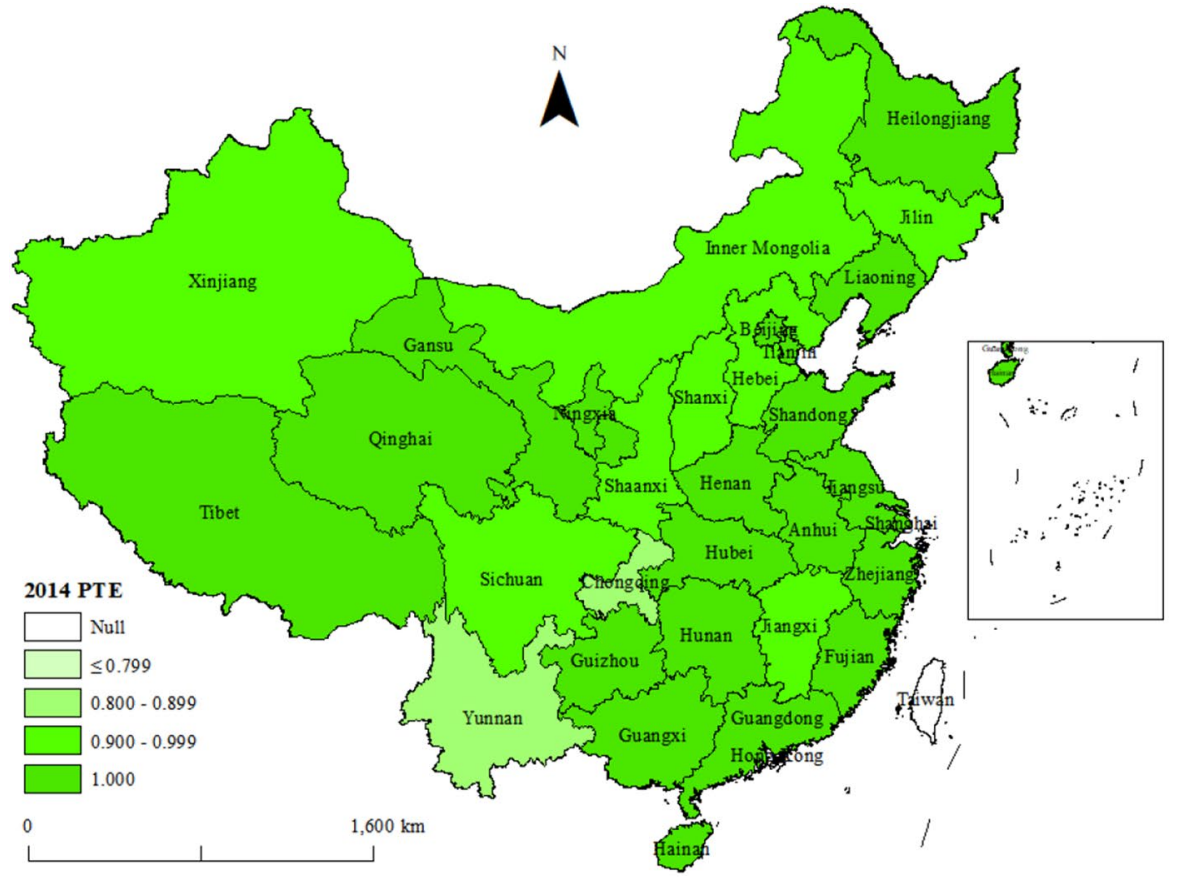

2014, the PTE

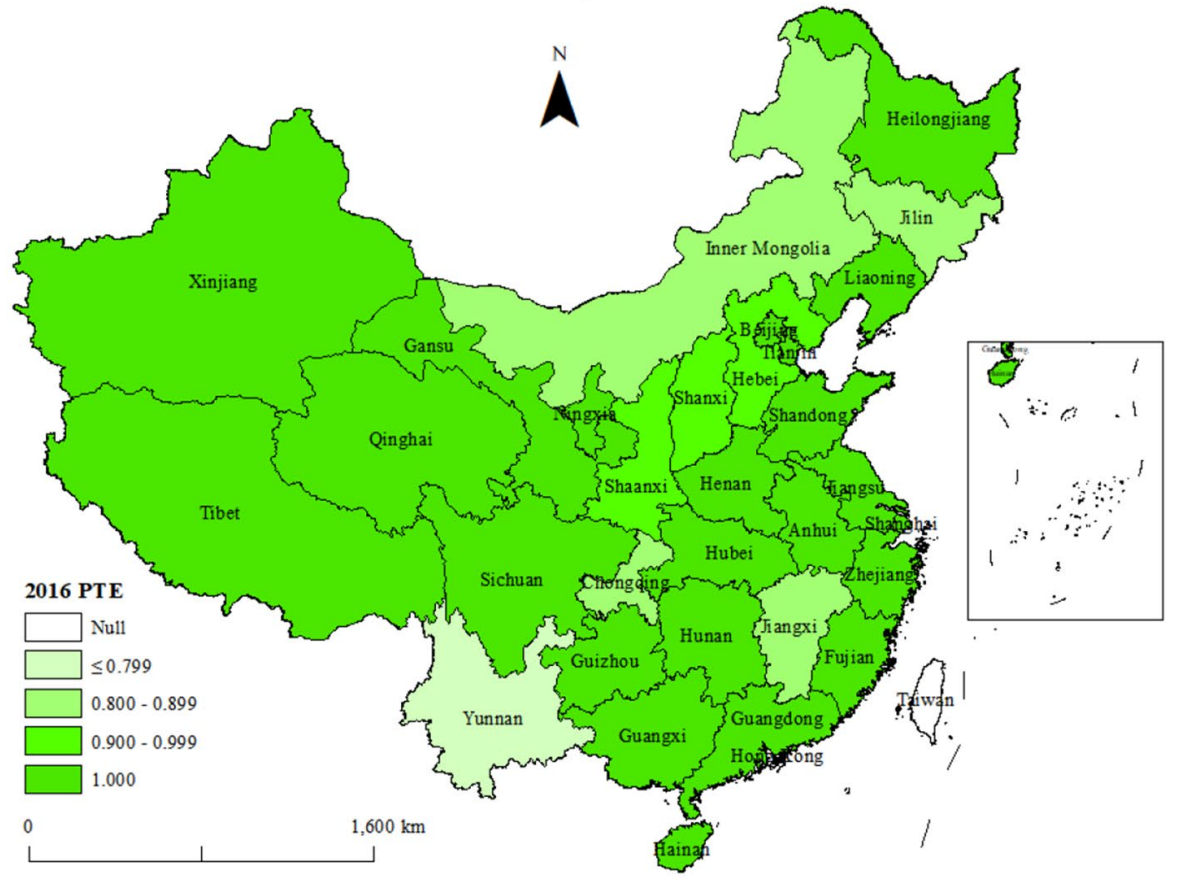

2016, the PTE

Fig. 2 Spatial characteristics of the PTE of public security in China 


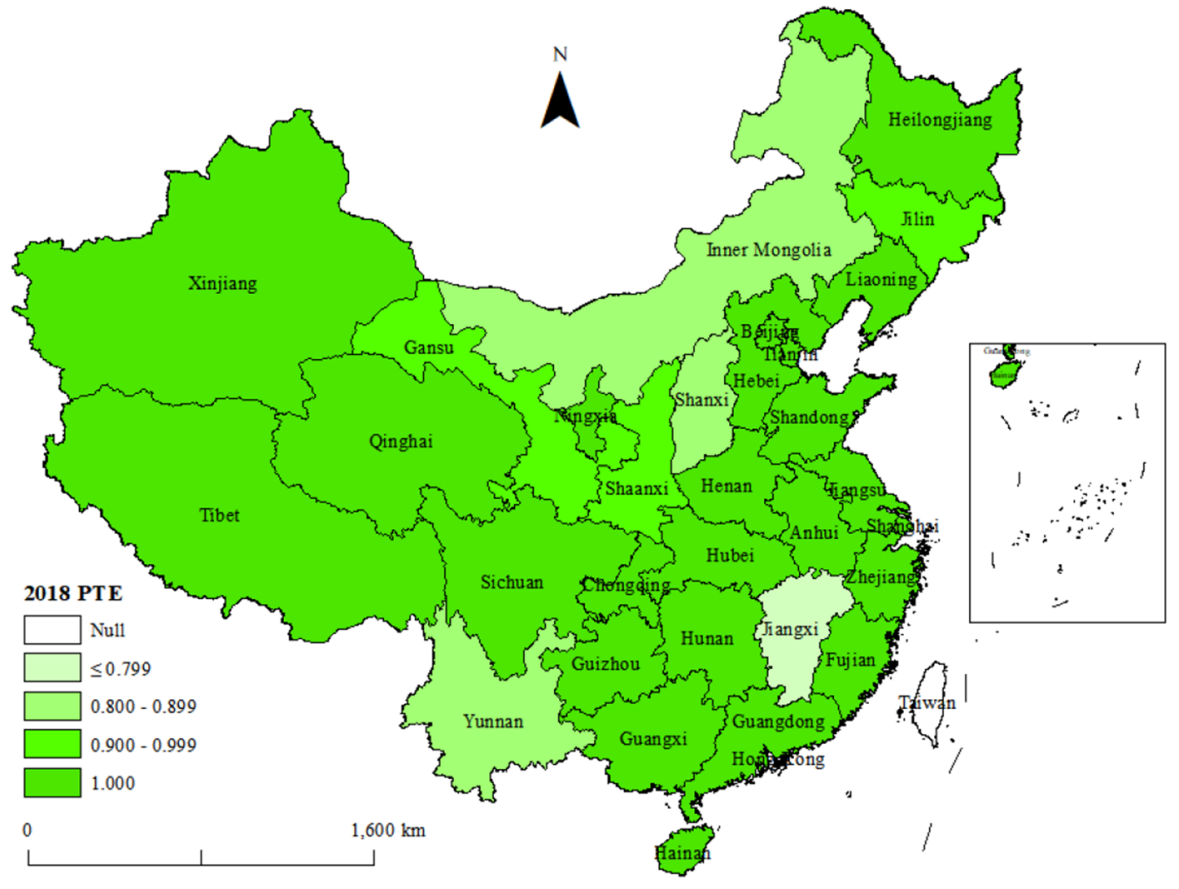

2018, the PTE

Fig. 2 (continued)

be improved by $4.4 \%$. Similarly, the public safety TE from 2014 to 2018 needs further improvement.

From 2014 to 2018, there were 19 (2014), 20 (2015), 19 (2016), 17 (2017), and 20 (2018) regions in China that demonstrated an effective proportion of public safety efficiency (Table 1), indicating that the safety inputs of these regions reached their optimal levels in the corresponding year. In other words, under certain conditions, the safety inputs of these regions were minimal.

According to the technical efficiency measurement results of various regions from 2014 to 2018, although Beijing's unemployment rate, traffic accident casualties, and direct economic losses from natural disasters were relatively low, and the per capita regional GDP was relatively high, its public safety input was relatively large, and the number of beds in health facilities and the daily treatment capacity of daily sewage in the output were low, which led to a low level of public safety efficiency from 2014 to 2015 . For Inner Mongolia, the public safety input was relatively low in 2016-2018, and its expected daily sewage treatment capacity and number of beds in health facilities were relatively low, and the registered unemployment rate and natural disasters in undesirable output were direct. Thus, the relatively high economic losses have led to the lowest technical efficiency.

The spatial characteristics of 2014, 2016, and 2018 TE of public safety in China are formulated in Fig. 1. The TEs of 19, 19, and 20 regions were effective in the years of 2014, 2016, and 2018, respectively. In addition, the TE of public safety 


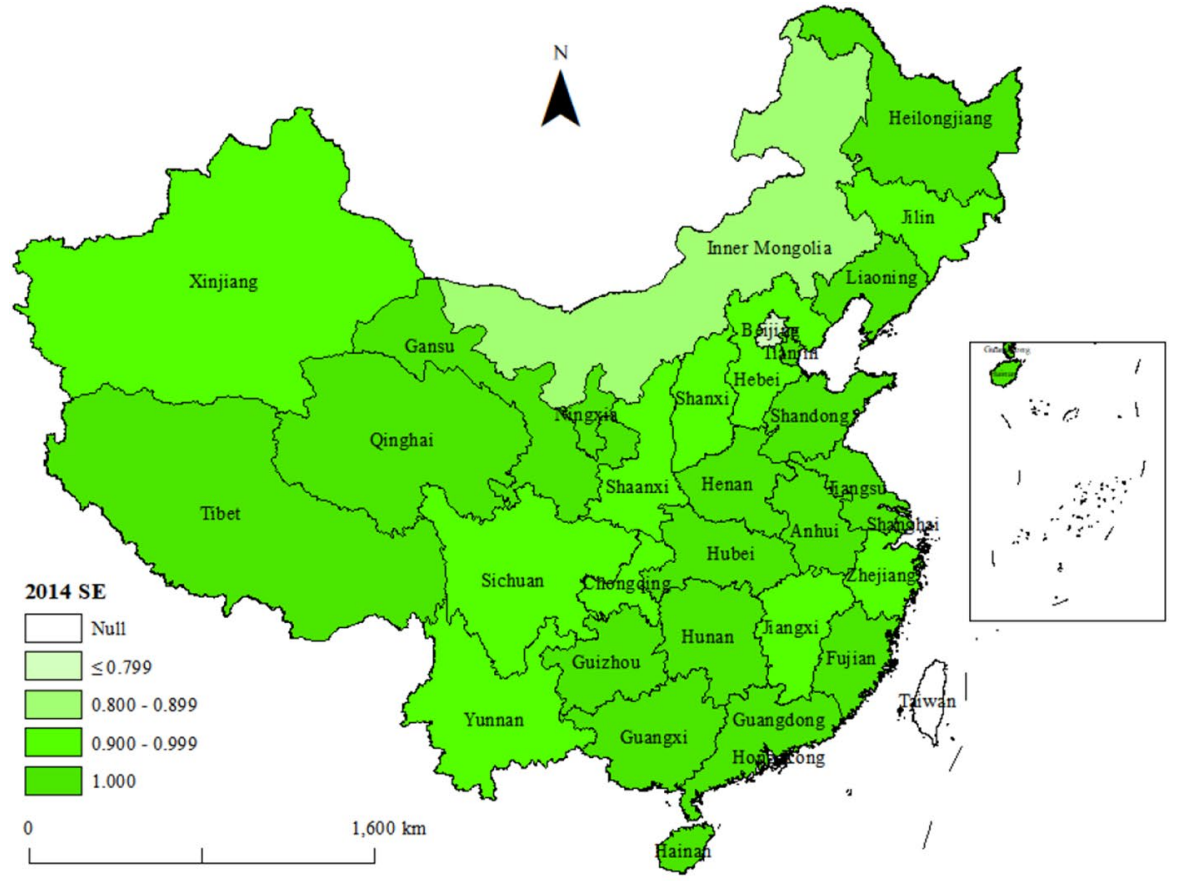

2014, the SE

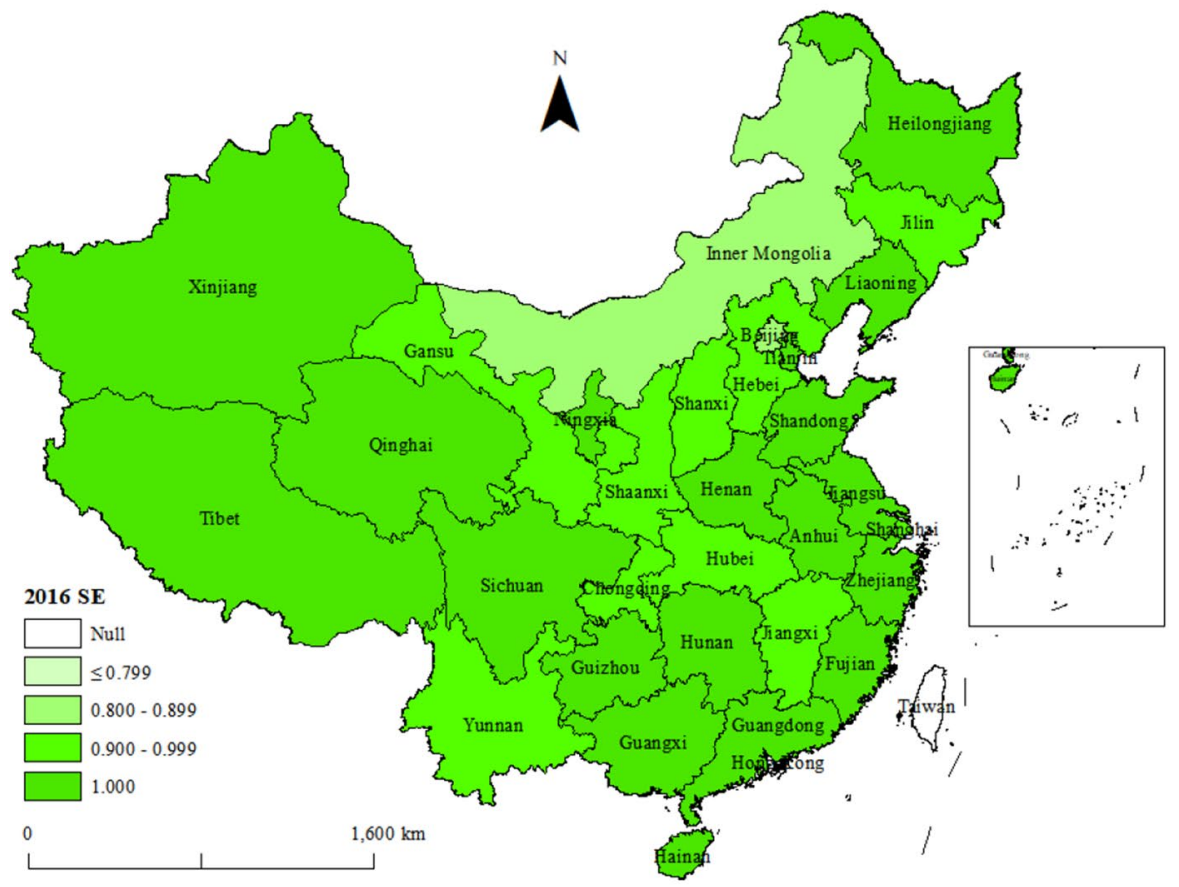

2016, the SE

Fig. 3 Spatial characteristics of the SE of public security in China 


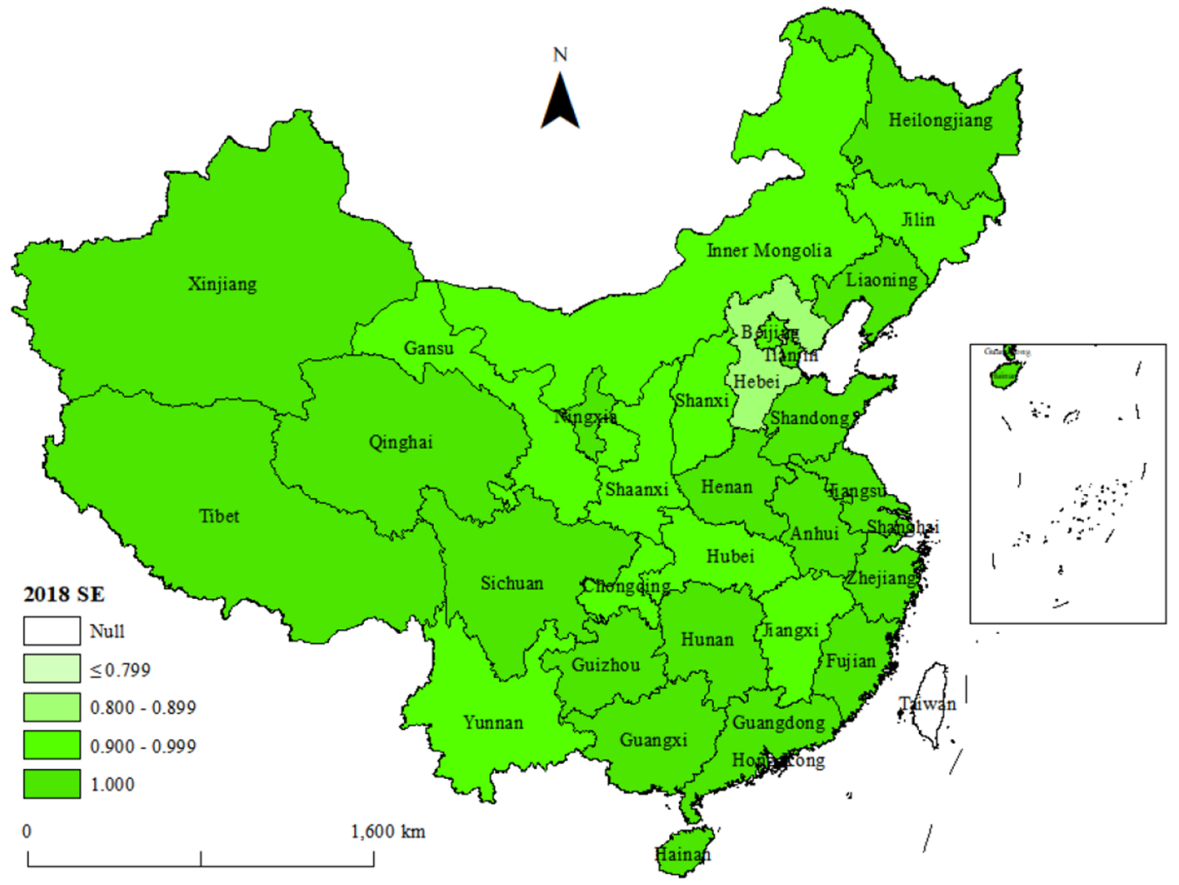

2018, the SE

Fig. 3 (continued)

efficiency in Tianjin, Liaoning, Heilongjiang, Jiangsu, Anhui, Fujian, Shandong, Henan, Hunan, Guangxi, Hainan, Guizhou, Tibet, and Ningxia 14 regions has been reached their effective levels for five consecutive years since 2014. From the TE analysis of these 14 areas, the findings are as following:

1. From the perspective of safety input: Public safety input in 14 regions where the technical efficiency reaches the effective value was polarized. The regions with low input were Tibet, Ningxia, and Hainan, while the regions with higher input levels were Henan, Shandong, and Jiangsu.

2. According to the expected output data, in terms of daily sewage treatment capacity, Liaoning, Shandong, and Jiangsu had relatively strong sewage treatment capacity, while Tibet, Ningxia, and Hainan had relatively weak sewage treatment capacity. The GDP per capita was relatively high in Tianjin, Fujian, and Jiangsu, and relatively low in Heilongjiang, Guangxi, Guizhou, and Tibet. For the number of beds in medical and health institutions, Shandong and Henan were relatively high, while Tianjin, Hainan, Ningxia, and Tibet were relatively low.

3. From the unexpected output data, the registered unemployment rate in urban units was lower in Hainan, Guangxi, Tibet, and Anhui, while those in Hunan, Fujian, Ningxia, Liaoning, and Heilongjiang were relatively high. The number of casualties in traffic accidents was relatively low in Tibet, Ningxia, and Hainan, and Guizhou, Guangxi, and Henan were relatively high. For direct economic losses 
of natural disasters, Tianjin, Hainan, Ningxia, Tibet, and Guangxi were lower, while Shandong was higher.

\subsubsection{Measured values and spatial characteristics of PTE and SE}

\section{(1) Spatial characteristics of PTE}

PTE and TE demonstrated similar trend in 31 regions in China, which means a yearly decrease in their average PTE from 2014 to 2018 (Table 1). Specifically, the average PTE of these regions was 0.977(2014), 0.970 (2015), 0.968(2016), 0.965 (2017), and 0.973 (2018), respectively. The mean PTE of these regions was less than 1, suggesting that the PTE of these regions still needs to be improved along with their allocation and utilization of public safety resources. The PTEs of 21(2014), 22(2015), 23(2016), 21(2017), and 24(2018) regions reached their effective levels, and only 19 of these regions achieved effective PTE levels for five consecutive years.

Accordingly, several characteristics can be extracted as follows (Fig. 2). First, in 2014, 21 regions reached the effective levels of PTE, among which 19 regions reached the effective levels of TE in the same year. In 2016, 23 regions achieved the effective levels of PTE, among which 19 regions achieved the effective levels of TE in the same year. In 2018, 24 regions achieved the effective levels of PTE, among which 20 regions achieved the effective levels of TE. Other regions did not achieve an effective level of TE because of their SE. The above-mentioned regions also showed diminishing returns to scale in the corresponding years, suggesting that their public safety investment mix should be readjusted. Second, the PTE of public safety in Hebei, Chongqing, Sichuan, and Xinjiang changed from ineffective to effective, while Gansu changed from effective to ineffective, and Shanxi, Inner Mongolia, Jilin, Jiangxi, Yunnan, and Shaanxi had been continually ineffective since 2014.

Overall, the evolving spatial of the PTE of public safety in 31 regions changed, with more rapid change in Sichuan than in Hebei, Chongqing, and Xinjiang. Hebei, Chongqing and Xinjiang's PTE achieved the effective level due to the three-folded reasons: the unexpected safety output indicators, unemployment rate, traffic accident casualties and direct economic losses of natural disasters continued to decline; the expected safety output indicators, sewage treatment capacity, GDP per capita, and the number of beds in health and medical institutions continued to rise; meanwhile, the investment in safety continued to increase, indicating that the performance of regional safety management was continuously improving. However, Gansu's unexpected safety output indicators continued to rise, and PTE was in an ineffective level, indicating that the performance of regional public safety management needs to be improved. The public security performance levels of Shanxi, Inner Mongolia, Jilin, Jiangxi, Yunnan, and Shaanxi were low, because of high non-expected safety output, low expected safety output, and relatively low public safety input. 


\section{(2) Spatial characteristics of SE}

Table 1 shows that from 2014 to 2018, the public safety SEs of all regions were all less than 1, indicating that these regions had an invalid SE, and that the actual public safety of these regions was still far from its optimal level. Specifically, the average SE of public safety of these regions was $0.978,0.973,0.981,0.982$, and 0.984 from 2014 to 2018, respectively. The average SE of these regions in each year was relatively stable and showed a gradual increase. A total of 19 (2014), 20 (2015), 19 (2016), 17 (2017), and 20 (2018) regions achieved an effective level of SE, suggesting that the economies of scale of these regions in the corresponding years were optimal and had CRS. Therefore, these regions must maintain their current scales of production. 14 regions achieved optimal returns to scale for five consecutive years from 2014 to 2018. Meanwhile, 10 (2014), 8 (2015), 11 (2016), 10 (2017), and 7 (2018) regions showed a DRS, indicating that having an excessive amount of inputs may drive regions to expand beyond their capacity. Five regions (Beijing, Hebei, Inner Mongolia, Chongqing, and Shaanxi) showed a DRS for five consecutive years, suggesting that these regions should strengthen and adjust their input elements to avoid unnecessary waste. Meanwhile, 2(Yunnan and Xinjiang), 3(Shanxi, Yunnan, and Xinjiang), 1(Jiangxi), 4(Jilin, Jiangxi, Yunnan, and Gansu), and 4(Shanxi, Jilin, Jiangxi, and Yunnan) regions showed an IRS from 2014 to 2018, respectively, showing that the revenues generated from these regions were greater than the increase in various factors of production and that the scale formed a bottleneck that restricted their public safety efficiency. However, Beijing was identified as the regions which did not achieve effective levels of TE for five consecutive years because of the impact of SE. Therefore, these regions should achieve TE by improving their SE. Although Beijing's public safety input was relatively large, public safety infrastructure input was insufficient with smaller number of beds in health facilities and the daily treatment capacity of daily sewage and other safety input. Because Beijing is a densely populated city, the input of public safety service facilities should be increased. For example, the input structure of public transportation, public health, natural disasters, and public safety should be improved to make it more reasonable, and to achieve coordination of public safety structures and scale efficiency.

Based on these results, the following two characteristics can be ascribed (Fig. 3). First, in 2014, the numbers of regions with an effective SE was the same with regions with an effective TE. In 2016 and 2018, the SEs of 19 and 20 regions were effective, respectively. Second, the SE of public safety in Sichuan and Xinjiang changed from ineffective to effective, while Hubei and Gansu changed from effective to ineffective, and Beijing, Hebei, Shanxi, Inner Mongolia, Jilin, Jiangxi, Chongqing, Yunnan, and Shaanxi had been continually ineffective since 2014. The unemployment rate in Sichuan and Xinjiang had dropped significantly, the expected safety output had increased, and scale efficiency had been achieved effectively. The unemployment rate and the number of casualties in traffic accidents had increased in Hubei and Gansu, and the sewage treatment capacity had declined, especially in the direct economy of natural disasters in Gansu in 2018. The sudden increase in losses resulted in the scale efficiency of these two regions not being effective. Beijing, 
Table 2 Variations in PTEC, SEC, TEC, TPC, an Malmquist index of public safety in China (2014-2018)

\begin{tabular}{|c|c|c|c|c|c|}
\hline Region & PTEC & SEC & TEC & $\mathrm{TPC}$ & Malmquist index \\
\hline Beijing & 1.000 & 1.069 & 1.069 & 0.902 & 0.964 \\
\hline Tianjin & 1.000 & 1.000 & 1.000 & 0.927 & 0.927 \\
\hline Hebei & 1.004 & 0.982 & 0.986 & 0.913 & 0.900 \\
\hline Liaoning & 0.980 & 1.000 & 0.981 & 0.933 & 0.915 \\
\hline Shanghai & 0.978 & 1.025 & 1.003 & 0.944 & 0.947 \\
\hline Jiangsu & 1.000 & 1.000 & 1.000 & 1.007 & 1.007 \\
\hline Zhejiang & 0.982 & 1.020 & 1.001 & 0.947 & 0.948 \\
\hline Fujian & 1.000 & 1.000 & 1.000 & 0.92 & 0.920 \\
\hline Shandong & 1.000 & 1.000 & 1.000 & 0.885 & 0.885 \\
\hline Guangdong & 1.000 & 1.000 & 1.000 & 0.898 & 0.898 \\
\hline Hainan & 1.000 & 1.004 & 1.004 & 0.911 & 0.915 \\
\hline Shanxi & 1.000 & 1.000 & 1.000 & 0.887 & 0.887 \\
\hline Jilin & 1.000 & 1.000 & 1.000 & 0.880 & 0.880 \\
\hline Heilongjiang & 0.962 & 0.999 & 0.961 & 0.897 & 0.862 \\
\hline Anhui & 1.000 & 1.000 & 1.000 & 0.916 & 0.916 \\
\hline Jiangxi & 1.000 & 1.000 & 1.000 & 0.897 & 0.897 \\
\hline Henan & 1.000 & 0.986 & 0.986 & 0.927 & 0.914 \\
\hline Hubei & 1.000 & 1.000 & 1.000 & 0.954 & 0.954 \\
\hline Hunan & 1.000 & 1.000 & 1.000 & 0.894 & 0.894 \\
\hline Inner Mongolia & 1.000 & 1.000 & 1.000 & 0.969 & 0.969 \\
\hline Guangxi & 1.000 & 1.000 & 1.000 & 0.868 & 0.868 \\
\hline Chongqing & 1.039 & 0.979 & 1.017 & 0.945 & 0.961 \\
\hline Sichuan & 1.004 & 1.006 & 1.010 & 0.952 & 0.961 \\
\hline Guizhou & 1.000 & 1.000 & 1.000 & 0.912 & 0.912 \\
\hline Yunnan & 1.000 & 1.000 & 1.000 & 0.936 & 0.936 \\
\hline Tibet & 1.000 & 1.000 & 1.000 & 0.842 & 0.842 \\
\hline Shaanxi & 1.013 & 0.992 & 1.004 & 0.945 & 0.949 \\
\hline Gansu & 0.991 & 0.991 & 0.982 & 0.911 & 0.895 \\
\hline Qinghai & 1.000 & 1.000 & 1.000 & 0.858 & 0.858 \\
\hline Ningxia & 1.000 & 1.000 & 1.000 & 0.878 & 0.878 \\
\hline Xinjiang & 1.011 & 1.001 & 1.012 & 0.943 & 0.954 \\
\hline Annual average & 0.999 & 1.002 & 1.000 & 0.915 & 0.916 \\
\hline
\end{tabular}

Hebei, Shanxi, Inner Mongolia, Jilin, Jiangxi, Chongqing, Yunnan, and Shaanxi had higher unemployment rates, lower sewage treatment capacity, and lower public safety input, making it difficult to achieve scale efficiency. Overall, the evolving spatial of the SE of public safety in 31 regions changed, with more rapid change in Hubei and Gansu than in Sichuan and Xinjiang. 


\subsection{Spatial variations of different public safety efficiencies}

\subsubsection{Annual average variation of each region's public safety efficiencies}

The total factor efficiency index of the public safety of 31 regions from 2014 to 2018 was calculated and the Malmquist index based on their public safety input and output data. The overall and individual trends were calculated and analyzed accordingly. Table 2 shows that the annual Malmquist indices of the 30 regions (except Jiangsu) over four years were all less than 1 , with an average of 0.916 . Their overall efficiency indices declined by $8.4 \%$ from 2014 to 2018 .

The decomposition of the TEC reveals that the SEC was the main factor affecting the decreasing TEC in Hebei, Heilongjiang, Henan, Chongqing, Gansu, and Shaanxi. Therefore, the public safety input level of these regions needs to be improved to enhance their TEC. Meanwhile, the change in PTEC was identified as the main factor influencing the declining TE in Liaoning, Shanghai, Heilongjiang, Gansu, and Zhejiang. Therefore, Liaoning, Shanghai, Heilongjiang, Gansu, and Zhejiang need to improve its resource allocation accordingly. A comprehensive analysis reveals that the growth of the Malmquist index of Heilongjiang and Gansu were constrained by the TEC, PTEC, and SEC. In this case, Heilongjiang and Gansu need to improve its input scale, resource allocation, and investments in science and technology.

\subsubsection{Annual average variations in the regional public safety efficiency}

Table 3 shows the average annual Malmquist indices of 31 regions and their decomposition. The Malmquist indices of these regions were all less than 1 (except 2015-2016), which means that the public safety efficiency of these regions had a downward trend from 2014 to 2018. From a structural perspective, the average value of TEC is 1 , indicating that the TEC is maintained at a stable level, but the average value of TEC had decreased by $8.5 \%$, indicating that the lack of technological progress was identified as the main factor influencing the growth of public safety efficiency of these regions.

Except for the PTEC greater than 1 in 2017-2018, the other three stages were all less than 1 , and the overall average value had decreased by $0.1 \%$, indicating that the resource elements had not been fully and effectively used in 2014-2017, while the resource elements in 2017-2018 reasonable allocation and improved utilization rate.

Table 3 Annual average variations in PTEC, SEC, TEC, TPC, and Malmquist of public safety in China (2014-2018)

\begin{tabular}{llllll}
\hline Year & PTEC & SEC & TEC & TPC & Malmquist Index \\
\hline $2014-2015$ & 0.992 & 0.994 & 0.987 & 0.850 & 0.838 \\
$2015-2016$ & 0.998 & 1.010 & 1.007 & 1.051 & 1.058 \\
$2016-2017$ & 0.996 & 1.001 & 0.998 & 0.901 & 0.898 \\
$2017-2018$ & 1.009 & 1.001 & 1.010 & 0.873 & 0.882 \\
Annual average & 0.999 & 1.002 & 1.000 & 0.915 & 0.916 \\
\hline
\end{tabular}




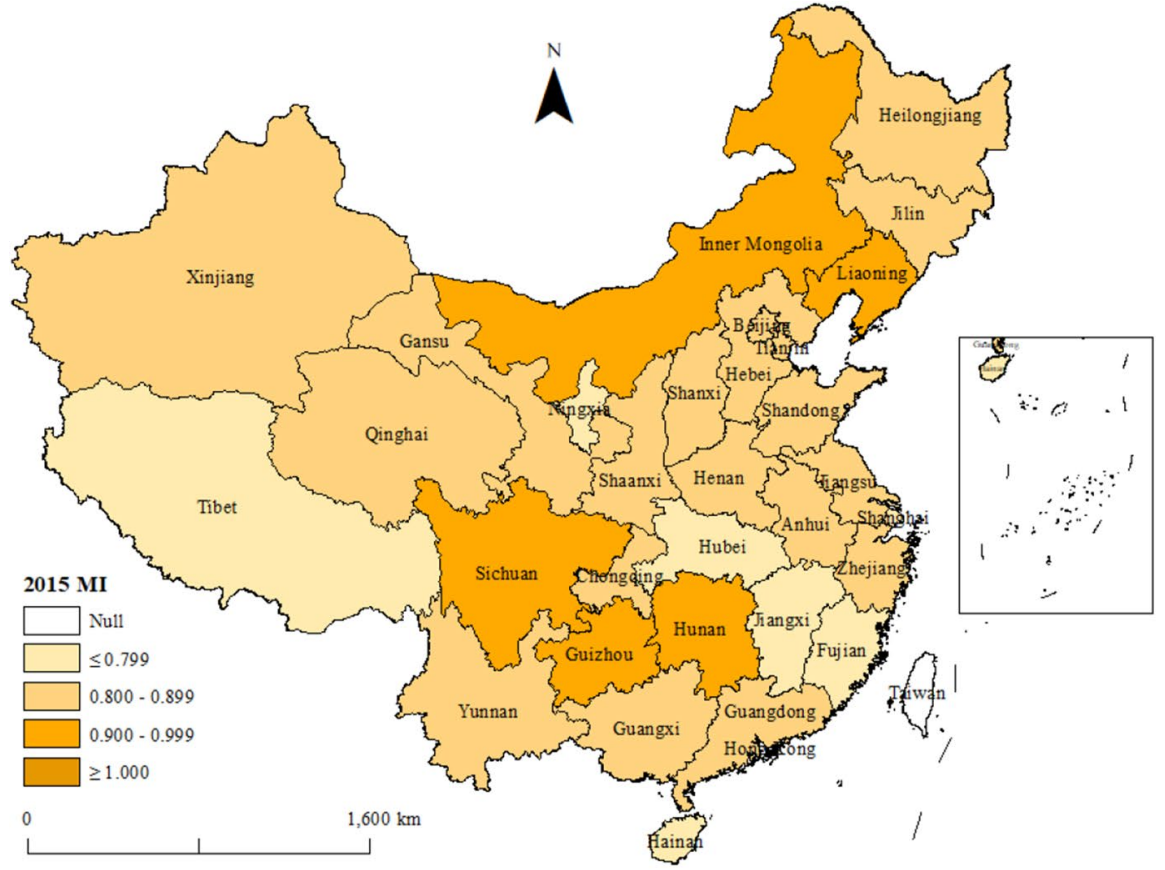

(a) Malmquist variation in 2015

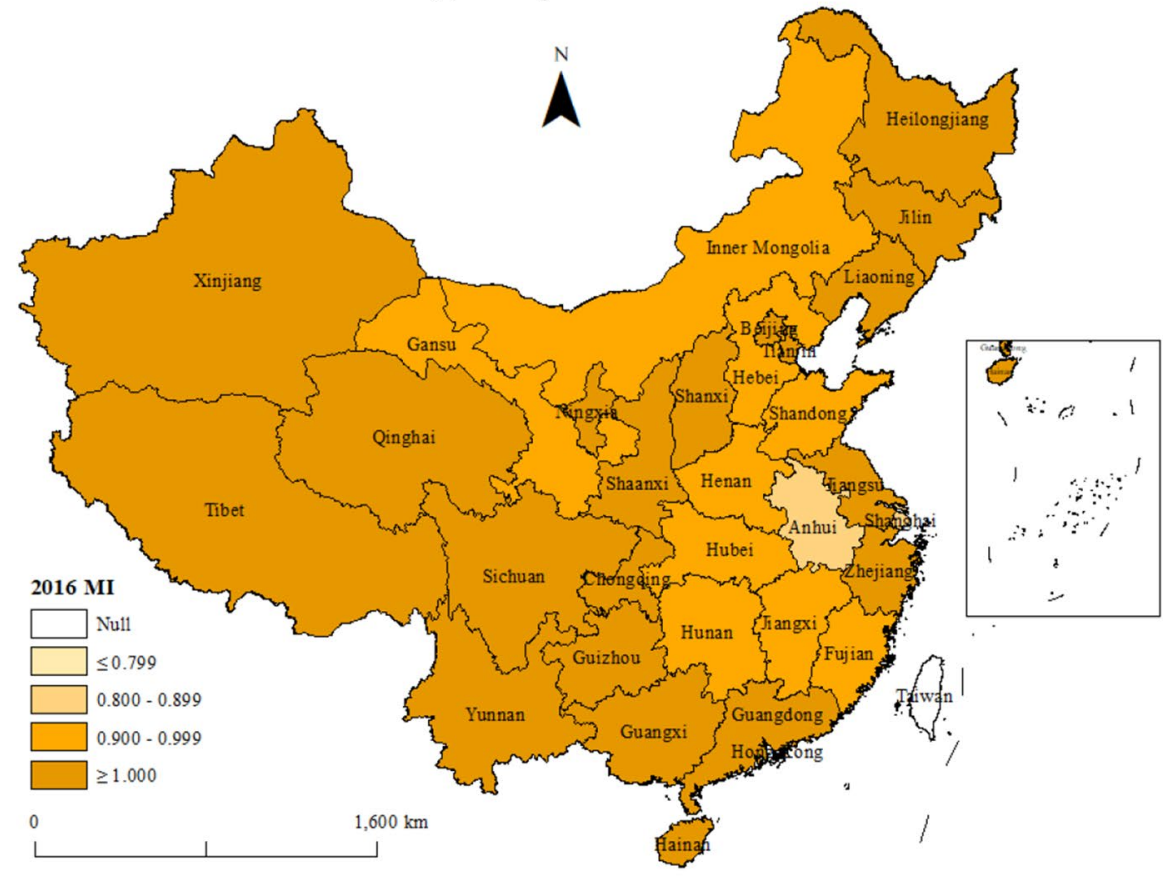

(b) Malmquist variation in 2016

Fig. 4 Spatial characteristics of the Malmquist variation of public security (2015-2018) 


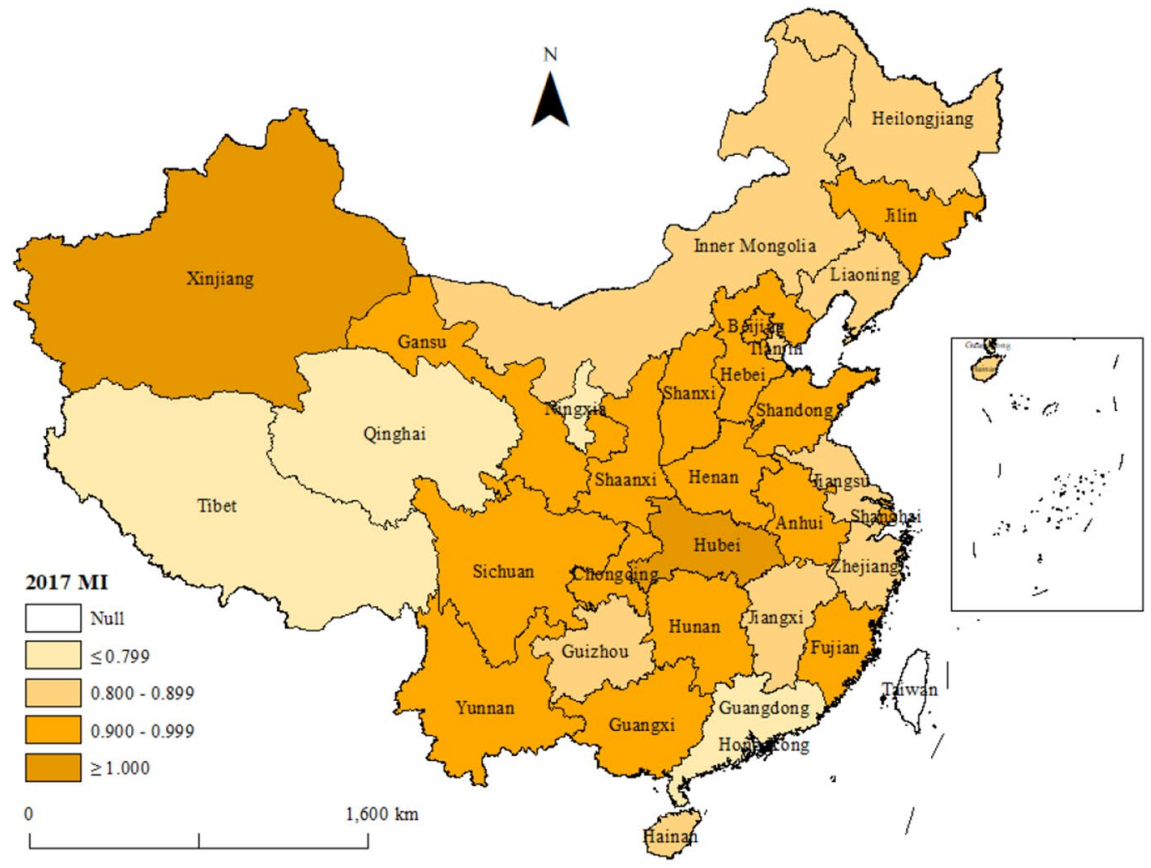

(c) Malmquist variation in 2017

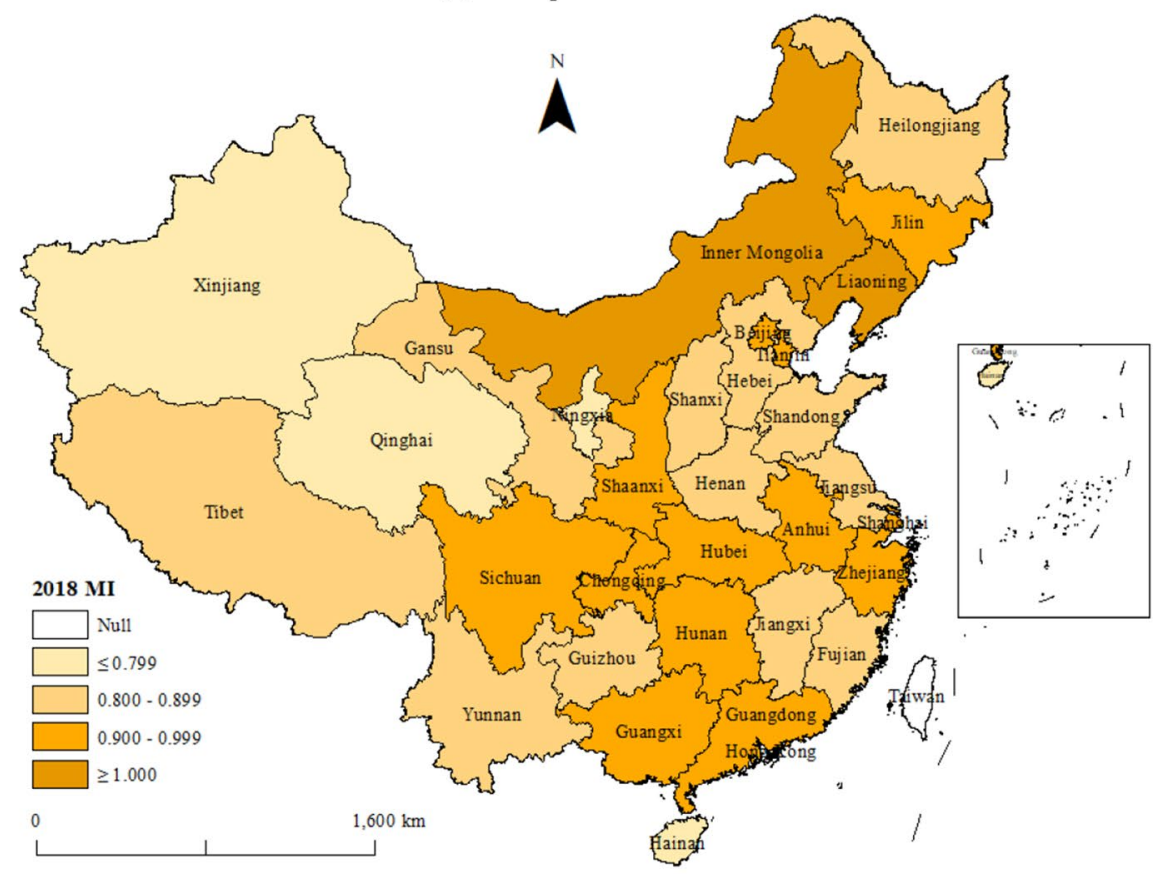

(d) Malmquist variation in 2018

Fig. 4 (continued) 
The overall mean of SEC was 1.002, less than 1 during 2014-2015 and greater than 1 during 2015-2018. Overall, insufficient development of PTEC was the main factor affecting the growth of regional public safety technical efficiency.

\subsubsection{Spatial characteristics of the variations in the Malmquist index}

The evolution of the Malmquist index of public safety of the 31 regions from 2014 to 2018 was generated through ArcMap (Fig. 4). In 2015, the Malmquist index of 31 regions public safety efficiency was less than 1 , due to insufficient technological progress in each region, and insufficient technical efficiency to drive the development of production efficiency, which in turn led to a drop in public safety efficiency in various regions. Among them, the public safety efficiency in Tibet had the largest decline compared with 2014, which can be mainly attributed to its decreasing TEC and lack of technical progress.

Nineteen regions (Fig. 4) had Malmquist indices of greater than 1 in 2016. These regions also demonstrated an increasing trend in their public safety efficiency, with Ningxia showing the fastest growth. Specifically, Ningxia had a Malmquist index of 1.491 , indicating that its public safety efficiency increased by $49.1 \%$ from 2014 to 2015. The improved public safety efficiency of Ningxia was mainly driven by its TPC. Jiangsu's Malmquist index, TEC, and TPC are all 1, indicating that its public safety production efficiency is maintained at a stable level. The other 11 regions demonstrated a downward trend in their public safety efficiency, among which Anhui showed the largest decrease. This region was mainly affected by the decrease in its TEC and TPC, and the decrease in TPC had the greatest influence on its public safety efficiency.

Hubei and Xinjiang were the two regions with Malmquist index greater than 1 in 2017. The improvement of the public safety efficiency in Xinjiang mainly stemed from technological progress. The improvement of Hubei's public safety efficiency mainly stemed from the improvement of technical efficiency, and the growth of scale efficiency served as the core driving force for the improvement of its public safety technical efficiency. The Malmquist index of the other 29 regions was all less than 1. Among them, Qinghai's public safety efficiency Malmquist index was the lowest, which was affected by TPC, PTEC, and SEC.

The only regions with a Malmquist greater than 1 were Liaoning and Inner Mongolia in 2018. The improvement of public safety efficiency in Liaoning mainly stemed from technological progress. The improvement of Hubei's public safety efficiency was mainly due to the improvement of TE, and the growth of PTE was the main driving force for the improvement of its public safety technical efficiency. The Malmquist productivity index of the other 29 regions was less than 1. Hainan demonstrated the largest decrease in its public safety efficiency from 2017 to 2018 because of its limited technical progress. 


\section{Conclusions, managerial implications, and limitations}

\subsection{Conclusion and discussion}

This study applied the DEA-BC ${ }^{2}$ model and the Malmquist index to evaluate the public safety efficiency of 31 regions in China. The following conclusions are drawn from the analysis:

First, the average TE, PTE, and SE of all 31 regions in 2014 and 2018 were less than 1, indicating that the TE was ineffective in China. These regions also showed a certain degree of redundancy in their public safety inputs, and their public safety resource utilization rate needs to be improved further. The TE, PTE, and SE of public safety efficiency in Tianjin, Liaoning, Heilongjiang, Jiangsu, Anhui, Fujian, Shandong, Henan, Hunan, Guangxi, Hainan, Guizhou, Tibet, and Ningxia 14 regions had reached their effective levels for five consecutive years from 2014 to 2018 , showing that these regions had high output efficiency, reasonable resource allocation, and optimal returns to scale.

Second, the average Malmquist indices of all 31 regions were less than 1 across all four years from 2014 to 2018 , revealing a downward trend in the overall public safety efficiency in China. From 2015 to 2016, reasonable allocation and use efficiency of public safety resources were identified as the primary drivers of the growth in public safety efficiency. Meanwhile, from 2014 to 2015, the TPC, PTEC, and SEC were identified as the primary drivers of the decline in public safety efficiency, from 2016 to 2017; the TPC and PTEC were identified as the primary drivers of the decline in public safety efficiency. From 2017 to 2018, the 31 regions in China were affected by the TPC, all of which significantly reduced their public safety efficiency. Therefore, both the TPC and TEC influenced the variations in the Malmquist index of these regions. In this case, these regions should strengthen and improve their public safety inputs, input elements allocation, and their utilization rate of public safety resources.

Third, the Malmquist indices of the 31 regions identified TPC as the main factor affecting the growth in public safety efficiency. However, the public safety efficiency of Beijing, Tianjin, Shanghai, Zhejiang, Fujian, Shandong, Guangdong, Hainan, Shanxi, Jilin, Anhui, Jiangxi, Hubei, Hunan, Inner Mongolia, Guangxi, Chongqing, Sichuan, Guizhou, Yunnan, Tibet, Shaanxi, Qinghai, Ningxia, and Xinjiang were also affected by the decline in their TPC. The Malmquist index of productivity growth of the 31 regions gradually decreased from 2014 to 2015 , 2016 to 2017 , and 2017 to 2018 . If the TPC cannot sufficiently drive an increase in its production efficiency, its public safety efficiency is reduced.

Based on the above research conclusions, the study reveals the following theoretical contributions. First, the selection of safety input and output indicators is the key to the evaluation of regional public safety efficiency. Based on previous research (Egilmez and McAvoy 2013; Hermans et al. 2009; Lu et al. 2016; Dearmond et al. 2011; Fung et al. 2010; Saunders et al. 2017), this study constructed four safety input indicators (i.e., local environmental protection investments, public safety investments, financial healthcare investments, and social 
safety and employment investments), three unexpected output indicators (i.e., unemployment rate, traffic accident casualties, and direct economic losses resulting from natural disasters), and three expected output indicators (i.e., sewage treatment capacity, GDP per capita, and number of beds in medical and health institutions). These indicators represent four aspects of regional natural disasters, public health, accidents, and social security, which are correlated and have validity (Liao and Hou 2009; Liu et al. 2005; Zhu and Lv 2011; Yu and Fang 2017). Through DEA analysis and calculation, the data results reflect the TE and SE of public safety.

Second, this study evaluates regional public safety efficiency from a macroscopic provincial perspective. Due to the characteristics of public safety management at the provincial level in China, the analysis of the efficiency and characteristics of provincial public safety management can help improve the structure and level of provincial public safety input-output system; it also contributes to the joint prevention and control of public safety in the region. Although many public safety issues tend to occur with a specific location rather than provincial- or metropolitan-wide, the prevention and control from the overall perspective of the provincial level is essential to solve safety issues faster and to prevent the spread of accidents. For example, the COVID-19 outbreak in late 2019, as a public health emergency, occurred in a specific region, but provincial-level prevention and control measures were put in place to prevent the spread of the epidemic in China. In addition, examining public safety input and output at the provincial level would clearly determine the safety structure of each region and further improve the scale efficiency.

\subsection{Managerial implications}

Comprehensively assessing the efficiency of public safety inputs can improve the efficiency of fund and management resource utilization and help regional governments understand how safety inputs are used and how their resource allocation can be optimized. Calculating public safety inputs-outputs is critical, as insufficient government safety investment could result in a high probability of accidents. Therefore, local government may lose public credibility, and the local government officials could be punished by higher administrative or central government. On the other hand, higher safety investment from the government is likely to result in lower rate of accidents. However, simply expending government investment is not the solution due to the opportunity costs (Ma et al. 2016). Therefore, a suitable approach should be developed to help these managers estimate the public safety inputs-outputs and make better decisions (Azadeh et al. 2017). The findings of the study suggest the following be taken into account when managing the public safety inputs and outputs of regions.

First, the public safety efficiency of 31 regions should be comprehensively considered using the input-output results from various aspects, and the size of scale cannot be judged from any single perspective. Beijing was recorded the lowest TE of public safety for five consecutive years. The analysis of each indicator reveals that Beijing had a low urban unemployment rate, number of traffic accident casualties, 
and direct economic losses from natural disasters, but the city had a high GDP per capita and comprehensive utilization rate of sewage treatment capacity in 2015. Moreover, Beijing showed high public safety inputs and a low number of beds in its healthcare institutions, thereby indicating a low level of public safety efficiency. Meanwhile, Tibet had low public safety inputs and low expected output. However, from the perspective of the undesired output data, Tibet has the lowest urban unemployment rate and number of traffic accident casualties. In other words, even though the economy and infrastructure in Tibet are relatively under developed, Tibet has an acceptable amount of safety inputs and its public safety efficiency is relatively high.

Second, local governments should allocate investment resources reasonably to improve the technical progress of the combination of safety input and output. According to the input data, Tibet, Ningxia, Hainan, Qinghai, Tianjin, and Fujian had low public safety inputs, while Shandong, Henan, and Liaoning had high public safety inputs. According to the expected output data, "Tianjin, Shandong, and Henan," "Fujian, Hainan, and Ningxia," and "Qinghai, Liaoning, and Tibet" had high, moderate, and low comprehensive utilization rates of industrial solid waste, respectively; "Tianjin, Fujian, Liaoning, and Shandong," "Ningxia, Hainan, and Qinghai," "Henan and Tibet" had high, moderate, and low GDP per capita, respectively; and "Shandong and Henan," "Liaoning and Fujian," and "Tianjin, Hainan, Qinghai, Ningxia, and Tibet" had a large, moderate, and few number of beds in their healthcare institutions, respectively. The findings of this study reveal that the growth of the regional Malmquist index is constrained by the TPC, PTEC, and SEC. In this case, each region needs to improve the input scale, resource allocation, and investments in science and technology.

\subsection{Research limitations}

This study uses the Malmquist index to analyze the characteristics and evolution of the public safety efficiency of 31 regions in China. However, the limitations of these indicators and the data availability may hinder the analysis of the determinants of public safety efficiency. Some of the variables selected in the paper seem to contain indirect relationships rather than direct causal relationships related to public safety. Some representative indicators, such as crime rate and environmental pollution index, were not selected in this study due to the data availability issue. Future research on the regional public safety efficiency should include additional variables and indices which direct causal relationships related to public safety to test with and complement this study. More data from official available sources should be further explored for developing long-term policies accordingly. In addition, the degree of impact of the key influencing factors and the formation mechanism of regional public safety efficiency should be further examined in future research.

Acknowledgements The author would like to thank Dr. Fang Meng, Associate Professor at the University of South Carolina, for her valuable help on the manuscript revising and editing. 


\section{References}

Al-Muharrami S (2008) An examination of technical, pure technical and scale efficiencies in GCC banking. Am J Finance Account 1(2):152-166

Aminbakhsh S, Gunduz M, Sonmez R (2013) Safety risk assessment using analytic hierarchy process (AHP) during planning and budgeting of construction projects. J Saf Res 46:99-105

Aven T, Hiriart Y (2011) The use of a basic safety investment model in a practical risk management context. Reliab Eng Syst Saf 96(11):1421-1425

Azadeh A, Salehi V, Mirzayi M, Roudi E (2017) Combinatorial optimization of resilience engineering and organizational factors in a gas refinery by a unique mathematical programming approach. Hum Factors Ergon Manuf 27(1):53-65

Banker RD (1984) Estimating most productive scale size using data envelopment analysis. Eur J Oper Res 17(1):35-44

Barros CP, Mascarenhas MJ (2005) Technical and allocative efficiency in a chain of small hotels. Int J Hosp Manag 24(3):415-436

Caves DW, Christensen LR, Herriges JA (1984) Consistency of residential customer response in time-ofuse electricity pricing experiments. J Econom 26:179-203

Chang YM (2013) Research on urban public safety evaluation. Chongqing University, China

Cui Q, Li Y (2015) The change trend and influencing factors of civil aviation safety efficiency: the case of Chinese airline companies. Saf Sci 75:56-63

Dearmond S, Smith AE, Wilson CL, Chen PY, Cigularov KP (2011) Individual safety performance in the construction industry: development and validation of two short scales. Accid Anal Prev 43(3):948-954

Egilmez G, McAvoy D (2013) Benchmarking road safety of U.S. states: a DEA-based Malmquist productivity index approach. Accid Anal Prev 53:55-64

Färe R, Grosskopf S, Lindgren B, Roos P (1992) Productivity changes in Swedish pharamacies 19801989: a non-parametric Malmquist approach. J Product Anal 3(1):85-101

Feng Y, Teo EAL, Ling FYY, Low SP (2014) Exploring the interactive effects of safety investments, safety culture and project hazard on safety performance: an empirical analysis. Int J Proj Manag 32(6):932-943

Feng Y, Zhang S, Wu P (2015) Factors influencing workplace accident costs of building projects. Saf Sci 72:97-104

Frey BS (2015) On the political economy of public service. Econ Public Serv. https://doi. org/10.1201/9781420016994.ch28

Fung IWH, Tam VWY, Lo TY, Lu LLH (2010) Developing a risk assessment model for construction safety. Int J Proj Manag 28(6):593-600

Golany B, Roll Y (1989) An application procedure for DEA. Omega (United Kingdom) J Man Sci 17(3):237-250

Gong XX, Lv J (2017) Dynamic safety efficiency evaluation of key nodes in maritime silk road. J Syst Eng 32:414-422

Gurcanli GE, Bilir S, Sevim M (2015) Activity based risk assessment and safety cost estimation for residential building construction projects. Saf Sci 80:1-12

Hermans E, Brijs T, Wets G, Vanhoof K (2009) Benchmarking road safety: lessons to learn from a data envelopment analysis. Accid Anal Prev 41(1):174-182

Hu SH, Yang GX, Qing JL (2009) Construction and evaluation of urban safety index system. Stat Decis 4:42-45

Khataie AH, Bulgak AA, Segovia JJ (2011) Activity-based costing and management applied in a hybrid decision support system for order management. Decis Supp Syst 52(1):142-156

Kong LA, Li W (2006) Study on coal mine safety and safety input of coal mine enterprise in China. J China Coal Soc 2:72-75

Kożuch B, Sienkiewicz-Małyjurek K (2014) New requirements for managers of public safety systems. Procedia Soc Behav Sci 149:472-478

Lewis HF, Sexton TR (2004) Data envelopment analysis with reverse inputs and outputs. J Product Anal 21(2):113-132

Li HX, Cai LM, Li Y (2013) Analysis of China's coal enterprise safety efficiency: based on DEA. China Saf Sci J 23:167 
Liao AH, Hou FJ (2009) Urban security assessment based on approaching ideal point and analytic hierarchy process. Public Saf 14:35-39

Lin QX (2003) Urban security and crisis management. Jiangnan Forum 5:7-8

Liu M, Zhao GM, Chen G (2005) The establishment of urban public safety system research. China Public Secur 1:10-18

López-Alonso M, Ibarrondo-Dávila MP, Rubio-Gámez MC, Munoz TG (2013) The impact of health and safety investment on construction company costs. Saf Sci 60:151-159

Lu M, Cheung CM, Li H, Hsu SC (2016) Understanding the relationship between safety investment and safety performance of construction projects through agent-based modeling. Accid Anal Prev 94:8-17

Luo Y (2004) Safety economics. Chemical Industry Press, Beijing

Luo Y, Pei JJ, Su L (2005) Design of safety index system for urban well-off society. China Saf Sci J $1: 24-28$

Ma Y, Zhao Q, Xi M (2016) Decision-makings in safety investment: an opportunity cost perspective. Saf Sci 83:31-39

Mengolini A, Debarberis L (2008) Effectiveness evaluation methodology for safety processes to enhance organisational culture in hazardous installations. J Hazard Mater 155(1):243-252

Miller P, Whynes D, Reid A (2000) An economic evaluation of occupational health. Occup Med (Chic Ill) 50:159-163

Nahangi M, Chen Y, McCabe B (2019) Safety-based efficiency evaluation of construction sites using data envelopment analysis (DEA). Saf Sci 113:382-388

National Bureau of Statistics (2019) Retrieved from http://www.stats.gov.cn/tjsj/ndsj/. Accessed 20 Feb 2019

Paradi JC, Zhu H (2013) A survey on bank branch efficiency and performance research with data envelopment analysis. Omega 41(1):61-79

Proag SL, Proag V (2014) The cost benefit analysis of providing resilience. Procedia Econ Finance 18:361-368

Ríos-Manríquez M, Muñoz Colomina CI, Rodríguez-Vilariño Pastor ML (2014) Is the activity based costing system a viable instrument for small and medium enterprises? The case of Mexico. Estud Gerenciales 30(132):220-232

Sato Y (2012) Optimal budget planning for investment in safety measures of a chemical company. Int J Prod Econ 140(2):579-585

Saunders LW, Kleiner BM, McCoy AP, Ellis KP, Smith-Jackson T, Wernz C (2017) Developing an interorganizational safety climate instrument for the construction industry. Saf Sci 98:17-24

Schmidt-Thomé P (2006) Natural and technological hazards and risks affecting the spatial development of European regions. Spec Pap Geol Surv Finl 42:7-16

Schmitz PW (2000) On the joint use of liability and safety regulation. Int Rev Law Econ 20(3):371-382

Sousa V, Almeida NM, Dias LA (2014) Risk-based management of occupational safety and health in the construction industry-part 1: background knowledge. Saf Sci 66:75-86

Tang SL, Lee HK, Wong K (1997) Safety cost optimization of building projects in Hong Kong. Constr Manag Econ 15(2):177-186

Tappura S, Sievänen M, Heikkilä J, Jussila A, Nenonen N (2015) A management accounting perspective on safety. Saf Sci 71:151-159

Tsai WH, Yang CH, Chang JC, Lee HL (2014) An activity-based costing decision model for life cycle assessment in green building projects. Eur J Oper Res 238(2):607-619

Yu D, Fang C (2017) The dynamics of public safety in cities: a case study of Shanghai from 2010 to 2025. Habitat Int 69:104-113

Zhang XR, Li SJ (2004) Safety science theory. China Labor and Social Security Publishing House, Beijing

Zhao YL (2006) Urban security index (ICS) model, structure and function analysis. J Hunan City Univ $15: 1-4$

Zhu ZW, Lv SP (2011) On urban community public safety management performance assessment. J Xi'an Jiaotong Univ (Soc Sci) 31:58-62

Zhu ZW, Zhang R, Zhou B (2006) Evaluation of public security in China's tourism destinations and analysis of related factors. China Adm Manag 1:39-42

Zhu ZW, Cai L, Duan DD (2011) Public security evaluation framework based on "Vulnerability-Capability" comprehensive perspective: formation and paradigm. China Adm Manag 8:101-106 
Zou YG (2016) The assessment of tourism security and its temporal and spatial pattern in tourism destination based on statistical data of 31 cities. China Soft Sci 2:56-66

Publisher's Note Springer Nature remains neutral with regard to jurisdictional claims in published maps and institutional affiliations. 